\title{
PENGARUH GAYA HIDUP DAN KUALITAS PELAYANAN TERHADAP KEPUTUSAN PEMBELIAN JASA PENGIRIMAN JNE EXPRESS CABANG BEKASI TAHUN 2021
}

\author{
*Mevia Puspita Ardhianti ${ }^{1}$, M.Arif Hernawan ${ }^{2}$, Ryan Firdiansyah Suryawan ${ }^{3}$, \\ 1,2 Institut Transportasi dan Logistik Trisakti \\ ${ }^{3}$ Sekolah Tinggi Tinggi Penerbangan Aviasi, Jakarta Barat, Indonesia \\ *Email Korespondensi: \\ arifhernawan1112@gmail.com
}

\section{ARTIKEL INFORMASI}

Diterima:

25 Desember 2021

Direvisi:

12 Januari 2022

Dipublikasi:

30 Januari 2022

\begin{abstract}
ABSTRAK
Penelitian ini bertujuan untuk mengetahui pengaruh Gaya Hidup, dan kualitas Pelayanan terhadap keputusan pembelian penggunaan jasa pengiriman JNE Express cabang Bekasi Tahun 2021. Metode penelitian ini menggunakan penelitian kuantitatif. Data yang digunakan adalah data primer dari responden pelanggan JNE Express. Penelitian ini menggunakan 50 responden sebagai sampel dari penelitian. Pengujian ini dilakukan dengan mengunakan program SPSS versi 25. Alat analisis yang digunakan adalah uji regresi linier berganda. Hasil penelitian Gaya Hidup $\left(\mathrm{X}_{1}\right)$ terhadap Keputusan Pembelian (Y) memiliki nilai $t_{\text {hitung }}>\mathrm{t}_{\text {tabel }}$ maka $\mathrm{H} 0$ ditolak dan Ha diterima. Dapat disimpulkan bahwa variabel Gaya Hidup $\left(\mathrm{X}_{1}\right)$ memberikan pengaruh yang positif dan signifikan terhadap variabel Keputusan Pembelian (Y). Hasil penelitian Kualitas Pelayanan $\left(\mathrm{X}_{2}\right)$ terhadap Keputusan Pembelian (Y) memiliki nilai $t_{\text {hitung }}>\mathrm{t}_{\text {tabe }} \mathrm{l}$ maka H0 ditolak dan Ha diterima. Dapat disimpulkan bahwa variabel Kualitas Pelayanan $\left(\mathrm{X}_{2}\right)$ memberikan pengaruh yang positif dan signifikan terhadap variabel Keputusan Pembelian (Y).
\end{abstract}

Kata Kunci: Gaya Hidup, Kualitas Pelayanan, Keputusan Pembelian

\section{PENDAHULUAN}

Keputusan pembelian merupakan sebuah proses ketika konsumen mengenal masalahnya, mencari informasi mengenai produk atau merek tertentu dan mengevaluasi secara baik masing-masing alternatif tersebut dapat memecahkan masalahnya, yang nantinya mengarah kepada keputusan pembelian (Tjiptono 2012), sedangkan menurut Menurut Schiffman dan Kanuk (2014) keputusan pembelian didefinisikan sebagai sebuah pilihan dari dua atau lebih alternatif pilihan, dalam keputusan pembelian terdapat faktor-faktor yang mempengaruhi pelanggan dari ikatan emosional yang terjalin antara pelanggan dan produsen setelah pelanggan menggunakan produk dan jasa dari perusahaan dan mendapati bahwa produk atau jasa tersebut memberi nilai tambah. Menurut Tjiptono (2012) antara lain : Nilai emosional, utilitas yang berasal dari perasaan atau afektif atau emosi positif yang ditimbulkan dari mengonsumsi produk. Pada intinya nilai emosional berhubungan dengan perasaan, yaitu perasaan positif apa yang akan dialami konsumen pada saat membeli produk. Nilai sosial, Nilai sosial merupakan 
nilai yang dianut oleh suatu konsumen, mengenai apa yang dianggap baik dan apa yang dianggap buruk oleh konsumen. Nilai kualitas, utilitas yang didapat dari produk karena reduksi biaya jangka pendek dan biaya jangka panjang. Nilai fungsional adalah nilai yang diperoleh dari atribut produk yang memberikan kegunaan (utility) fungsional kepada konsumen nilai ini berkaitan langsung dengan fungsi yang diberikan oleh produk atau layanan kepada konsumen (HESTANTO, 2021). Dalam tercapainya tujuan perusahaan, keputusan pembelian sangat berperan penting agar hasil yang diinginkan perusahaan tercapai dengan maksimal dengan mengikuti peraturan yang ditetapkan oleh perusahaan tersebut.

Kelancaran dan kesuksesan suatu jasa pengiriman juga di pengaruhi oleh gaya hidup dan kualitas pelayanan agar konsumen dapat memutuskan akan memakai jasa pengiriman yang sesuai dengan kebutuhan mereka. Kotler (2011: 189) menyatakan gaya hidup seseorang adalah pola hidup seseorang dalam dunia kehidupan sehari-hari yang dinyatakan dalam kegiatan, minat dan pendapat (opini) yang bersangkutan (Kaharu \& Budiarti, 2016) . Dengan adanya kasus COVID 19 sejak tahun lalu, pemerintah menganjurkan masyarakat untuk membatasi aktivitas apapun termasuk berbelanja di luar rumah yang tentunya membuat gaya hidup masyarakat berubah, bahkan membuat gaya hidup masyarakat menjadi konsumtif Dalam artian luas, konsumtif merupakan perilaku konsumsi yang boros dan berlebihan, lebih mendahulukan keinginan daripada kebutuhan, serta tidak ada skala prioritas (Vicynthia, 2010).

Menurut Rossanty dan Nasution (2018), tanda-tanda perilaku konsumtif dapat timbul jika Anda mulai sering tertarik mengikuti suatu gaya hidup atau membeli barang-barang tertentu demi image (MEILINDA TRISILIA, S.SI., 2020). Apalagi dengan banyaknya promo besar besaran pada aplikasi online dapat membuat masyarakat tidak berfikir panjang untuk membeli banyak barang, dengan adanya gaya hidup terbaru ini tentunya sangat menguntungkan bagi pihak jasa pengiriman, maka dari itu keputusan pembelian sangat mendukung aktivitas pengiriman jasa pengiriman barang yang sudah menjadi sebuah trend yang di pilih oleh masyarakat dalam memenuhi kebutuhan sehari hari seperti sandang pangan dan papan. Terdapat beberapa hal yang ikut serta menjadi penyumbang naiknya pengiriman logistik dalam layanan jasa pengiriman barang seperti para pelaku usaha di e-commerce dan para pelaku usaha UMKM (Usaha Mikro, Kecil, dan Menengah) dan home industri lainnya, yang saat ini makin perkembang pesat. Menurut KBBI sendiri, ekspedisi adalah suatu aktivitas atau kegiatan pengiriman barang atau bisa diartikan juga sebagai perusahaan pengiriman barang.(Kamus Besar Bahasa Indonesia (KBBI), n.d.). dengan bertambah banyak nya jumlah pengiriman saat ini banyak perusahaan jasa pengiriman yang baru terjun menjadi pesaing baru agar jasa yang di tawarkan dapat menarik keputusan pembelian konsumen.

Dengan Layanan pengiriman barang yang bertambah banyak, masyakarat dapat memilih jasa tersebut sesuai dengan kebutuhan, misalnya setiap jasa pengiriman pasti mempunyai kelebihan masing masing dalam memenuhi kebutuhan masyarakat, bahkan gaya hidup dapat mempengaruhi pemakaian jasa tersebut dikarenakan dalam perusahaan biasanya memiliki beberapa varian jenis layanan. Salah satunya pada perusahaan JNE EXPRESS atau Jalur Nugraha Ekakurir merupakan perusahaan berpusat di jakarta yang memiliki cabang tersebar di seluruh Indonesia dan bergerak dalam bidang jasa pengiriman logistik. Dibawah naungan PT Tiki Jalur Nugraha Ekakurir yang merupakan perusahaan pengiriman terbesar di Indonesia. Perusahaan ini didirikan pada tanggal 26 November 1990 dengan nama PT Tiki Jalur Nugraha Ekakurir oleh Soeprapto Suparno.

Pada awal berdirinya, perusahaan ini didirikan sebagai perintis salah satu divisi dari PT Citra van Titipan Kilat (TiKi). Beberapa unit kegiatan yang dilakukan oleh JNE antara lain urusan kepabeaan, impor barang, dokumen serta pengantaran. Bukan hanya melayani pangsa pasar domestik saja, JNE juga turut melayani urusan pengantaran barang dan dokumen dari luar negeri untuk masuk ke Indonesia(W, 2021). Kegiatan pengiriman yang biasa di lakukan pada setiap agen JNE di tempat diawali dengan melayani pelanggan yang datang langsung ketempat, atau biasanya karyawan akan datang ke tempat pelanggan yang ingin di pick up langsung dari rumah, di tempat agen tersebut, karyawan agen akan menunggu kurir gudang untuk menjemput barang dan membuat laporan data barang atau resi. Beberapa jenis varian layanan JNE akan menentukan kecepatan pengiriman dan biaya yang di keluarkan antara lain : OKE (Ongkos Kirim Ekonomis), REG (Reguler), YES (Yakin Esok Sampai), SPS / SS (Super Speed), CTC (City to City), TRC (Truck) dan lain sebagainya. Dari beberapa jenis varian tersebut yang terbaik bergantung pada kebutuhan pelanggan ingin lebih cepat atau tidaknya, dan tentunya harus siap membayar lebih (CHANDRA, 2016). Dengan adanya pertumbuhan industri logistik dan e-commerce di masa pandemi membuat PT Tiki Jalur Nugraha Ekakurir (JNE) sepanjang 2020 mengalami peningkatan 
kinerja tercatat tumbuh 30\%. Ujar Vice President Marketing JNE, Eri Palgunadi (Mahadi, n.d.) Walaupun menguntungkan pihak jasa pengiriman tetap saja ada beberapa kendala, semenjak pemerintah melakukan strategi dengan mengadakan Penerapan Pembatasan Sosial Berskala Besar (PSBB) pada tahun kemarin yang dimulai dari pulau Jawa hingga di seluruh indonesia, diikuti tahun ini pemerintah juga melakukan Pemberlakuan Pembatasan Kegiatan Masyarakat (PPKM), oleh karena itu kebutuhan gaya hidup masyarakat pun berubah, masyarakat banyak menggunakan aplikasi e-commerce untuk berbelanja guna memenuhi kebutuhan mobilitas sehari-hari, sehingga permintaan transaksi melalui online sangat melonjak tinggi, yang mengakibatkan masalah baru dalam dunia pengiriman barang seperti keterlambatan pengiriman, pelayanan yang kurang memadai, yang mengakibatkan kekhawatiran akan merusak kepercayaan masyarakat dan mempengaruhi minat keputusan pembelian terhadap perusahaan jasa pengiriman. perumusan masalah diatas, maka tujuan dari penelitian ini adalah ; Untuk mengidentifikasi dan menguji pengaruh antara gaya hidup terhadap keputusan pembelian penggunaan jasa pengiriman Jne Express cabang bekasi tahun 2021, Untuk mengidentifikasi dan menguji pengaruh antara kualitas pelayanan terhadap keputusan pembelian penggunaan jasa pengiriman Jne Express cabang bekasi tahun 2021, Untuk mengidentifikasi dan menguji pengaruh gaya hidup dan kualitas pelayanan terhadap keputusan pembelian penggunaan jasa pengiriman Jne Express cabang bekasi tahun 2021.

Perumusan masalah diatas, maka tujuan dari penelitian ini adalah ; Untuk mengidentifikasi dan menguji pengaruh antara gaya hidup terhadap keputusan pembelian penggunaan jasa pengiriman Jne Express cabang bekasi tahun 2021, Untuk mengidentifikasi dan menguji pengaruh antara kualitas pelayanan terhadap keputusan pembelian penggunaan jasa pengiriman Jne Express cabang bekasi tahun 2021, Untuk mengidentifikasi dan menguji pengaruh gaya hidup dan kualitas pelayanan terhadap keputusan pembelian penggunaan jasa pengiriman Jne Express cabang bekasi tahun 2021.

\section{KAJIAN PUSTAKA}

Manajemen adalah ilmu dan seni dalam menggabungkan suatu proses, fasilitas, ide, sumber daya, dan orang-orang untuk menciptakan dan juga menjual barang dan jasa yang berharga untuk memberikan keuntungkan, T.H Nelson dalam Sarinah \& Muljadi, (2014). Kemudian"menurut G.R Terry dalam Sarinah \& Muljadi, (2014) bahwa manajemen merupakan prosedur umum yang mencakup pengorganisasian, pelaksanaan, perencanaan, juga pemantauan dalam memutuskan dan berusaha mencapai tujuan dengan menggunakan sumber daya manusia dan lainnya. Selanjutnya menurut James Stoner dalam Sarinah \& Muljadi, (2014) Manajemen dapat diartikan sebagai sebuah proses dalam mengorganisir, memimpin, merencanakan, dan mengawasi usaha anggota organisasi, serta penggunaan seluruh sumber daya organisasi untuk mencapai tujuan yang telah ditentukan (Muljadi A.J, Sarinah, 2014). Menurut beberapa uraian di atas dapat di simpulkan bahwa manajemen adalah suatu proses yang menggabungkan SDM dan lainnya yang nantinya akan menghasilkan suatu produk berupa barang dan jasa agar memberikan keuntungan dan agar tujuan tercapai. Menurut (Gunawan, 2015) mengatakan bahwa "logistik merupakan ilmu dan seni yang mengatur sekaligus mengkontrol arus informasi, barang, energi, dan sumber daya lainnya, seperti produk, jasa dan manusia, dari sumber produksi ke pasar dengan tujuan mengoptimalkan pengguna modal."

Manajemen logistik merupakan suatu aktivitas mengelola barang melalui proses perencanaan, pengadaan, penyimpanan, distribusi, pemeliharaan, dan penghapusan untuk memenuhi tujuan yang telah ditentukan. Manajemen logistik merupakan bagian dari Manajemen Rantai Pasokan (Supply Chain Management), menurut para ahli terkait dengan manajemen rantai pasok dan manajemen logistik sebagai berikut: Menurut (Heizer, J.\& Render, 2011)"Supply chain management adalah kegiatan pengelolaan suatu rangka untuk memperoleh raw material menjadi barang setengah jadi dan juga barang jadi kemudian dikirim melalui kegiatan distribusi. Kegiatan ini mencakup fungsi pembelian melalui pengadaan barang yang berhubungan antara pemasok dengan distributor.Menurut Blanchard, (2021) mengatakan bahwa "Supply chain management (SCM) is the management of a network of interconnected business involved in the provision of product an service packages required byend to the end customers and consumers in a supply chain. Supply chain management all movement and storage of raw materials, work-inprocess inventory, and finished goods frompoint of origin to point of consumption." Dari beberapa pengertian di atas penulis menyimpulkan bahwa Manajemen Logistik merupakan aktivitas pengelolaan suatu barang yang melalui berbagai proses yang akan di olah maupun di kirim melalui distribusi agar memenuhi tujuan yang ditentukan. 
Menurut Setiadi (2010:148), gaya hidup didefinisikan sebagai, cara hidup yang didefinisikan oleh bagaimana orang menghabiskan waktu mereka, apa yang mereka pikirkan tentang diri mereka sendiri dan juga dunia sekitarnya. Kemudian dilanjutkan dengan penelitian Minor dan Mowen (2002) di dalam jurnal Rahayu dan Alimudin (2015, hal.4) menyatakan bahwa: Gaya hidup adalah menunjukkan bagaimana orang hidup, bagaimana membelanjakan uangnya dan bagaimana mengalokasikan waktu. Sehingga dapat disimpulkan bahwa gaya hidup adalah pola hidup seseorang yang dinyatakan dalam kegiatan, minat, dan pendapatnya dalam membelanjakan uangnya dan bagaimana mengalokasikan waktu. Menurut Kotler (2011: 189) dalam (Kaharu \& Budiarti, 2016) menyatakan gaya hidup seseorang adalah pola hidup seseorang dalam dunia kehidupan seharihari yang dinyatakan dalam kegiatan, minat dan pendapat (opini) yang bersangkutan. Gaya hidup melukiskan keseluruhan pribadi yang berinteraksi dengan lingkungannya. Gaya hidup mencerminkan sesuatu yang lebih dari kelas sosial di satu pihak dan kepribadian di pihak lain. Aktivitas, minat dan opini (AIO) dipergunakan untuk meneliti kategori gaya hidup seorang konsumen seperti kreatifitas dalam memasak, sikap terhadap tayangan televisi, kebersihan rumah, sikap dan penerapan terhadap ajaran agama dan lain sebagainya.

Gaya hidup mencerminkan pola konsumtif yang menggambarkan pilihan seseorang untuk bagaimana ia mempergunakan waktu dan uangnya. Gaya hidup mencerminkan pola konsumsi yang menggambarkan pilihan seseorang bagaimana ia menggunakan waktu dan uang (Sumarwan, 2011) (Azizah, 2020). Dari beberapa uraian diatas penulis menyimpulkan bahwa gaya hidup merupakan pilihan seseorang untuk melakukan kegiatan dan mengalokasikan waktu guna memenuhi kebutuhan dan menunjukan bentuk kehidupan mereka. Menurut yang dikutip oleh Goetsch dan Davis (1994) Tjiptono, (2012), kualitas dapat diartikan sebagai "kondisi dinamis yang berhubungan dengan produk, jasa, sumber daya manusia, proses, dan lingkungan yang memenuhi atau melebihi harapan”. Menurut Zeithaml, Parasuraman, dan Berry, (dalam Radhitiyo et al., 2015) Service Quality (kualitas layanan) adalah ukuran seberapa baik suatu layanan menemui kecocokan dengan harapan pelanggan. Penyelenggaraan kualitas layanan berarti melakukan kompromi dengan harapan pelanggan dengan tata cara yang konsisten. Kualitas dapat diartikan sebagai totalitas dari karakteristik suatu produk (barang dan jasa) yang menunjang kemampuan dalam memenuhi kebutuhan. Kuaitas juga sering diartikan sebagai segala sesuatu yang memuaskan pelanggan atau sesuai dengan persyaratan atau kebutuhan, (agung Kurniawan dalam Arhamni, 2015). Menurut Zamke, Ron dan Schaft, Dick dalam Arhamni, (2015) kualitas jasa adalah membandingkan harapan mereka terhadap suatu pelayanan dengan kenyataan atau pengalaman yang mereka dapatkan atas pelayanan. Dari berbagai uraian diatas penulis menyimpulkan bahwa kualitas pelayanan suatu bentuk pemenuhan harapan dalam segi produk maupun jasa yang dapat memenuhi dan memuaskan harapan pelanggan.

Menurut Kotler \& Keller (2012) dalam Elfa Setiawan (2018) keputusan pembelian adalah Konsumen melalui serangkaian tahapan untuk mengidentifikasi masalah, mencari informasi atau data dari produk dan merek, dan mengevaluasi seberapa baik setiap produk atau merek dalam memecahkan masalah, yang mengarah pada proses pengambilan keputusan pembelian untuk membeli atau menggunakan layanan. Sedangkan menurut Nitisusastro (2012) dalam Elfa Setiawan (2018) keputusan pembelian atau menggunakan barang dan jasa memerlukan serangkaian penilaian dan mendapatkan informasi atau data tentang merek, serta meneliti berbagai pilihan merek untuk produk sejenis sebelum memutuskan suatu pembelian merek. Pendapat lain menurut Haider \& Shakib (2018) dalam (Eshra \& Beshir, 2019) keputusan membeli konsumen mengacu pada pendekatan yang terlibat ketika individu atau kelompok memilih, membeli, memanfaatkan atau kumpulan produk, layanan, konsep atau pengalaman yang sesuai dengan kebutuhan dan keinginan mereka. Dari berbagai pengertian di atas diatas penulis menyimpulkan keputusan pembelian adalah keputusan yang dilakukan oleh konsumen untuk melakukan pengambilan keputusan pembelian barang atau jasa. Dengan cara memilih dan mengevaluasi dari banyaknya"merek. Kerangka Pemikiran dalam penelitian ini sebagai berikut ;

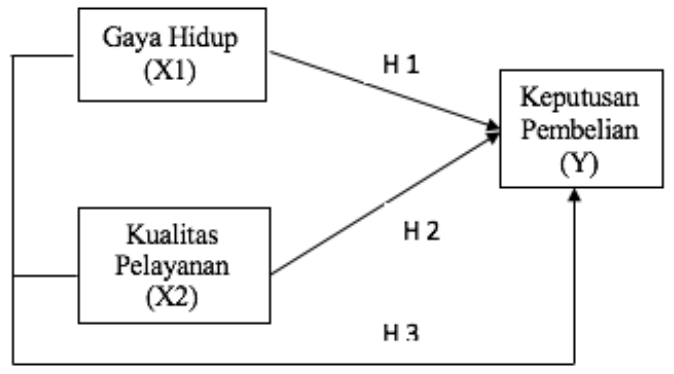

Gambar 1. Kerangka Berpikir 
Hipotesis penelitian sebagai berikut H1: "Diduga terdapat pengaruh yang signifikan antara gaya hidup terhadap keputusan pembelian".

H2: "Diduga terdapat pengaruh yang signifikan antara kualitas pelayanan terhadap keputusan pembelian".

H3: "Diduga terdapat pengaruh yang signifikan antara gaya hidup, kualitas pelayanan

Terhadap keputusan pembelian"

\section{METODE}

Metode penelitian yang digunakan adalah kualitatif dengan dengan melakukan survei untuk Pendekatan penelitian ini menggunakan metode penelitian kuantitatif. Penelitian kuantitatif adalah penelitian empiris yang datanya berbentuk angka-angka. Metode Kuantitatif adalah metode penelitian yang berlandaskan pada filsafat positivisme, digunakan untuk meneliti pada populasi atau sampel tertentu dan untuk menguji hipotesis yang telah ditetapkan.

\section{HASIL DAN PEMBAHASAN}

Dari hasil yang telah diuji oleh peneliti, menunjukan dan menjelaskan bahwa hasil instrumen data yang telah diisi oleh responden dalam rangka pengukuran pengaruh gaya hidup dan kualitas pelayanan terhadap keputusan pembelian jasa pengiriman JNE Express cabang Bekasi valid dan reliabel. Hasil tersebut selanjutnya didapatkan bahwa gaya hidup dan kualitas pelayanan berpengaruh positif dan signifikan terhadap keputusan pembelian penggunaan jasa JNE Express cabang Bekasi secara parsial maupun simultan.

Analisis Pengaruh Gaya Hidup Terhadap Keputusan Pembelian

Berdasarkan hasil dari perhitungan pada uji parsial (uji t) dipenelitian ini mendapatkan nilai tHitung $=3,431$ sedangkan ttabel $=2,010$. Karena tHitung lebih besar dari ttabel yaitu 3,431 > 2,010 maka Ha diterima dan H0 ditolak yang menunjukan bahwa variabel gaya hidup mempunyai pengaruh yang signifikan terhadap keputusan pembelian jasa pengiriman JNE Express cabang Bekasi. Hal ini menunjukan bahwa hipotesis yang terdapat di Bab I, terbukti benar bahwa ada pengaruh gaya hidup terhadap keputusan pembelian jasa pengiriman JNE Express cabang Bekasi. Hasil penelitian ini diperkuat oleh hasil penelitian terdahulu yang dilakukan oleh (Wijaya, 2017) dimana Gaya hidup berpengaruh positif dan signifikan terhadap keputusan pembelian.

Analisis Pengaruh Kualitas Pelayanan Terhadap Keputusan Pembelian

Berdasarkan hasil dari perhitungan pada uji parsial (uji t) dipenelitian ini mendapatkan nilai tHitung $=2,631$ sedangkan ttabel $=2,010$. Karena tHitung lebih besar dari ttabel yaitu 2,631 > 2,010 maka Ha diterima dan H0 ditolak yang menunjukan bahwa variabel kualitas pelayanan mempunyai pengaruh yang signifikan terhadap keputusan pembelian jasa pengiriman JNE Express cabang Bekasi. Hal ini menunjukan bahwa hipotesis yang terdapat di Bab I, terbukti benar bahwa ada pengaruh kualitas pelayanan terhadap keputusan pembelian jasa pengiriman JNE Express cabang Bekasi.

Analisis Pengaruh Gaya Hidup Dan Kualitas Pelayanan Terhadap Keputusan Pembelian

Berdasarkan hasil perhitungan uji analisis regresi berganda, peneliti mendapatkan hasil $\mathrm{Y}=1,998+0,507$ $\mathrm{X} 1+0,350 \mathrm{X} 2$. Konstanta sebesar 1,998 menyatakan bahwa jika ada nilai gaya hidup (X1) dan kualitas pelayanan (X2), maka keputusan pembelian (Y) nilainya 1,998. Hasil koefisien regresi X1 sebesar 0,507 menyatakan bahwa setiap penambahan 1 (satu) nilai pada gaya hidup (X1) akan meningkatkan variabel keputusan pembelian (Y) sebesar 0,507 kali pada konstanta 1,998. Hasil koefisien regresi (X2) sebesar 0,350 menyatakan bahwa setiap penambahan 1 (satu) nilai pada variabel kualitas pelayanan (X2) akan meningkatkan variabel keputusan pembelian (Y) sebesar 0,350 kali pada konstanta 1,998. Berdasarkan hasil analisis korelasi berganda, peneliti mendapatkan hasil $(\mathrm{R})=0,913$ yang berarti hubungan variabel Gaya hidup (X1), dan kualitas pelayanan (X2) secara bersama-sama memberikan kontribusi terhadap variabel keputusan pembelian (Y) sebesar $83,4 \%$ sisanya ditentukan variabel lain diluar model adalah sangat kuat.

Berdasarkan hasil uji simultan (uji F), peneliti mendapatkan hasil $F_{\text {Hitung }}$ sebesar 118,310. Sedangkan angka kritis nilai $F_{\text {tabel }}$ dengan derajat bebas pembilang 2 dan derajat penyebut 47 pada $\alpha=0,05$ sebesar 3,20. Dengan demikian $\mathrm{F}_{\text {Hitung }}(118,310)>\mathrm{F}_{\text {tabel }}(3,20)$, maka $\mathrm{H0}$ ditolak dan Ha diterima. Hal ini menunjukan bahwa model regresi variabel gaya hidup dan kualitas pelayanan signifikan terhadap keputusan pembelian jasa pengiriman JNE Express cabang Bekasi. Hal ini menunjukan bahwa hipotesis yang terdapat di Bab I, terbukti benar bahwa ada pengaruh gaya hidup, dan kualitas pelayanan terhadap keputusan pembelian jasa pengiriman JNE Express cabang Bekasi. Berdasarkan hasil uji koefisien determinasi $\left(R^{2}\right)$, peneliti mendapatkan hasil sebesar 0,834 yang 
menunjukan bahwa gaya hidup $\left(\mathrm{X}_{1}\right)$, dan kualitas pelayanan $\left(\mathrm{X}_{2}\right)$ mampu menjelaskan keputusan pembelian $(\mathrm{Y})$ sebesar $83,4 \%$ sedangkan sisanya $16,6 \%$ dapat diuraikan bahwa terdapat faktor-faktor lain yang tidak diteliti dalam penelitian ini.

\section{KESIMPULAN DAN SARAN}

Berdasarkan pembahasan hasil pengolahan data yang dilakukan menggunakan program SPSS 25 yang dilakukan oleh penulis, sehingga pada bab terakhir ini penulis menarik sebagian kesimpulan mengenai penelitian ini yang berjudul "Pengaruh Gaya Hidup, Dan Kualitas Pelayanan Terhadap Keputusan Pembelian Jasa pengiriman JNE Express cabang Bekasi" yaitu sebagai berikut: Pengaruh Gaya Hidup (X1) terhadap Keputusan Pembelian (Y) Pada penelitian ini menunjukan hasil bahwa Gaya Hidup memiliki pengaruh yang positif dan signifikan terhadap Keputusan Pembelian JNE Express cabang Bekasi, Pengaruh Kualitas Pelayanan (X2) terhadap Keputusan Pembelian (Y) Pada penelitian ini menunjukan hasil bahwa kualitas pelayanan memiliki pengaruh yang positif dan signifikan terhadap Keputusan Pembelian JNE Express cabang Bekasi, Hasil penelitian ini menunjukan bahwa Gaya Hidup, dan kualitas pelayanan secara bersama-sama memiliki pengaruh yang positif dan signifikan terhadap Terhadap Keputusan Pembelian JNE Express cabang Bekasi.

\section{Daftar Pustaka}

Anjani Dewinta Novia, Budi Lestari Retno, J. R. (2020). ANALISIS PENGARUH KEPERCAYAAN KUALITAS PELAYANAN SERTA GAYA HIDUP TERHADAP KEPUTUSAN PEMBEIAN DI ECOMMERCE LAZADA (STUDI KASUS PADA MAHASISWA STIE MDP). Jurnal Ilmiah, 274-282. https://core.ac.uk/download/pdf/153523783.pdf

Azizah, N. S. (2020). Pengaruh Literasi Keuangan, Gaya Hidup Pada Perilaku Keuangan Pada Generasi Milenial. Prisma (Platform Riset Mahasiswa Akuntansi), 01(02), 92-101.

Batjalery, S. (2019). ANALISA BAURAN PEMASARAN (7P) UNTUK MENENTUKAN STRATEGI PEMASARAN DALAM MENINGKATKAN VOLUME PEBatjalery, S. (2019). ANALISA BAURAN PEMASARAN (7P) UNTUK MENENTUKAN STRATEGI PEMASARAN DALAM MENINGKATKAN VOLUME PENJUALAN (Studi Kasus Pada HomeIndustry CV Mel. Jurnal Progresif Manajemen Bisnis (Jipmb), VI(4), 2354-5682. https://doi.org/10.35724/jies.v7i2.507

CHANDRA. (2016). Mengenal jenis layanan JNE. Utekno.Com. https://utekno.com/mengenal-jenis-layananjne-13188/

CITRA ANITA RAHMAH, S. E. (2020). Pengaruh Kualitas Pelayanan Dan Emosional Terhadap Kepuasan Pelanggan Pada Honda Idk 2 Medan. Manajemen, 12(2), 30-44.

Elfa Setiawan. (2018). HARGA TERHADAP KEPUTUSAN MENGGUNAKAN JASA KURIR. 1(2), 166-178.

Eshra, N., \& Beshir, N. (2019). Effect of Consumer Attitude towards SMS Advertising and Demographic Features on Egyptian Consumers Buying Decision. Journal of Marketing Management, 7(2), 2333-6099. https://doi.org/10.15640/jmm.v7n2a8

Farid M.Y. (2015). TERHADAP KEPUASAN PELANGGAN ( Studi pada konsumen salon mobil Autowax Semarang ) SKRIPSI.

Ghozali, I. (2018). Aplikasi analisis Multivariate dengan program IBM SPSS 25.

Gunawan. (2015). Pengantar Tranposrtasi dan Logistik, Cetakan Kedua.

Heizer, J.\& Render, B. (2011). Operations Management. (Tenth). IGRASS 2014.

Hendayani, R. (2011). Mari berkenalan dengan manajemen logistik. Alfabeta.

HESTANTO. (2021). Keputusan PembelianNo Title. Www.Hestanto.Web.Id. https://www.hestanto.web.id/keputusan-pembelian/

Intan Lina Katrin, H.p Diyah Setyorini, M. (2018). PENGARUH PROMOSI TERHADAP KEPUTUSAN PEMBELIAN DI RESTORAN JAVANA BISTRO BANDUNG. Gastronomy Tourism, 3(1), 246-254.

Kaharu, D., \& Budiarti, A. (2016). Pengaruh Gaya Hidup, Promosi, dan Kualitas Produk terhadap Keputusan Pembelian pada Cosmic. Jurnal Ilmu Dan Riset Manajemen, ISSN : 2461-0593, 5(3), 1-24.

Kamus Besar Bahasa Indonesia (KBBI). (n.d.). Kamus Besar Bahasa Indonesia (KBBI). Kbbi.Web.Id. Retrieved August 7, 2021, from https://kbbi.web.id/ekspedisi 
Mahadi, T. (n.d.). Di tengah pandemi, kinerja JNE tumbuh 30\%. Industri.Kontan.Co.Id. Retrieved August 6, 2021, from https://industri.kontan.co.id/news/di-tengah-pandemi-kinerja-jne-tumbuh-30

MEILINDA TRISILIA, S.SI., M. S. (2020). COVID-19 DAN PERUBAHAN GAYA HIDUPNo Title. Binus.Ac.Id. https://binus.ac.id/malang/2020/09/covid-19-dan-perubahan-gaya-hidup/

Muljadi A.J, Sarinah, S. (2014). Pengantar Manajemen Edisi Revisi. Mitra Wacana Media.

Musay, F. P. (2013). PENGARUH BRAND IMAGE TERHADAP KEPUTUSAN PEMBELIAN. Administrasi Bisnis, 3(2). file:///C:/Users/Asus/Downloads/141-534-1-PB.pdf

Novenda, R., Hidayat, W., \& Listyorini, S. (2013). Pengaruh Citra Merek Dan Kualitas Pelayanan Dengan Minat Memakai Jasa Sebagai Variabel Intervening Terhadap Keputusan Pemakaian Jasa Pengiriman Paket Pt Pos Indonesia. Jurnal Ilmu Administrasi Bisnis S1 Undip, 2(4), 198-205.

Paramita Boni Lestari, S. H. 2017. (2017). ANALISIS FUNGSI MANAJEMEN LOGISTIK DI BADAN PEMBERDAYAAN MASYARAKAT DAN KELUARGA BERENCANA KOTA SURABAYA. 5(1), 40-42. 